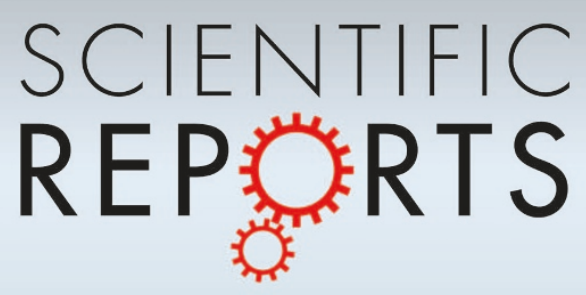

OPEN Mechanical properties and structural

SUBJECT AREAS:

METALS AND ALLOYS

GLASSES

MECHANICAL PROPERTIES \title{
features of novel Fe-based bulk metallic glasses with unprecedented plasticity
}

\author{
Weiming Yang ${ }^{1,2}$, Haishun Liu', Yucheng Zhao' ${ }^{1}$ Akihisa Inove ${ }^{3,4}$, Kemin Jiang $^{3}$, Juntao Huo ${ }^{3}$, Haibo Ling ${ }^{5}$, \\ Qiang Li $^{5} \&$ Baolong Shen ${ }^{2}$
}

Received

11 June 2014

Accepted

11 August 2014

Published

29 August 2014

Correspondence and requests for materials should be addressed to

H.S.L. (liuhaishun@

126.com) or B.L.S.

(blshen@seu.edu.cn)

\begin{abstract}
${ }^{1}$ School of Mechanics and Civil Engineering, State Key Laboratory for Geomechanics and Deep Underground Engineering, School of Sciences, China University of Mining and Technology, Xuzhou 2211 16, People's Republic of China, ${ }^{2}$ School of Materials Science and Engineering, Southeast University, Nanjing 211189 , People's Republic of China, ${ }^{3}$ Key Laboratory of Magnetic Materials and Devices, Ningbo Institute of Materials Technology \& Engineering, Chinese Academy of Sciences, Ningbo 315201 , People's Republic of China, ${ }^{4}$ Department of Physics, King Abdulaziz University, Jeddah 21589 , Saudi Arabia, ${ }^{5}$ School of Physics Science and Technology, Xinjiang University, Urumqi, Xinjiang 830046, People's Republic of China.
\end{abstract}

Fe-based bulk metallic glasses (BMGs) have attracted great attention due to their unique magnetic and mechanical properties, but few applications have been materialized because of their brittleness at room temperature. Here we report a new $\mathrm{Fe}_{50} \mathrm{Ni}_{30} \mathrm{P}_{13} \mathrm{C}_{7} \mathrm{BMG}$ which exhibits unprecedented compressive plasticity $(>20 \%)$ at room temperature without final fracture. The mechanism of unprecedented plasticity for this new Fe-based BMG was also investigated. It was discovered that the ductile $\mathrm{Fe}_{50} \mathrm{Ni}_{30} \mathrm{P}_{13} \mathrm{C}_{7} \mathrm{BMG}$ is composed of unique clusters mainly linked by less directional metal-metal bonds which are inclined to accommodate shear strain and absorbed energy in the front of crack tip. This conclusion was further verified by the X-ray photoelectron spectroscopy and ultraviolet photoelectron spectroscopy experiments of $\mathrm{Fe}_{80-\mathrm{x}} \mathrm{Ni}_{\mathrm{x}} \mathrm{P}_{13} \mathrm{C}_{7}(x=0,10,20,30)$ and $\mathrm{Fe}_{72-\mathrm{x}} \mathrm{Ni}_{\mathrm{x}} \mathrm{B}_{20} \mathrm{Si}_{4} \mathrm{Nb}_{4}(x=0,7.2,14.4,21.6,28.8)$ glassy systems. The results also indicate a strong correlation between the $p$ - $d$ hybridization and plasticity, verifying that the transition from brittle to ductile induced by $\mathrm{Ni}$ addition is due to the change of bonding characteristics in atomic configurations. Thus, we can design the plasticity of Fe-based BMGs and open up a new possible pathway for manufacturing BMGs with high strength and plasticity.

\footnotetext{
- e-based bulk metallic glasses (BMGs) have attracted great research development interests ever since their - first synthesis in $1995^{1}$ because of the combination of superior chemical ${ }^{2}$, magnetic and mechanical properties $^{3-6}$, and the low cost of manufacture ${ }^{7,8}$. Especially, after the discovery of Fe-based BMGs, they were considered to possess promising applications as magnetic, structural and surface coated materials ${ }^{5,9}$. However, they usually fracture catastrophically when deformed at room temperature, often undergoing only a few percent of plastic strain in compressions $s^{10-15}$, which limits their widespread applications ${ }^{16}$. Meanwhile, the catastrophic fracture of these BMGs is one of the well documented phenomena in materials science and engineering, but little research has been done to understand the mechanism and the possible improvement for the fracture ${ }^{17}$. Therefore, it would be important from a commercial perspective to enhance the plasticity of Fe-based BMGs at room temperature. The understanding of the deformation mechanism has also become a major goal over the recent decades ${ }^{10,18}$. Experimentally, the emerging strategy to couple the attractive properties of BMGs with plasticity is to introduce a second phase $\mathrm{e}^{19}$, which reflects and/or absorbs shear bands. This strategy seems particularly successful when the spacing of the second phase coincides with the critical crack length of the metallic glassy matrix phase ${ }^{20}$. On the other hand, higher Poisson's ratio is suggested to be one of the important factors in designing a glassy alloy to alleviate the brittleness ${ }^{21}$. However, these hypotheses have not been fully verified, and the method for controlling the evolution of shear bands in BMGs to improve their plasticity remains a challenge. Theoretically, several structural models such as free volume $e^{22}$, shear transformation zone ${ }^{23}$ and efficient cluster packing theories $^{24,25}$ have been proposed to explain the plastic flow and fracture; whereas these models in terms of packing based on atomic size and configuration have failed to interpret the nature of atomic bonding in BMGs, which is indispensable for a better understanding of their mechanical behavior involved in brittle to ductile transition. Recently, theoretical calculations have illuminated that the hybrid character of interatomic bonds of multicompositions may contribute to the intrinsic plasticity versus brittleness of BMGs by controlling the bond
} 
mobility ${ }^{17,26,27}$. In contrast, the order parameter obtained from experiments to characterize the nature of bond mobility and its evolution on alloying in BMGs is still lacking.

In this paper, we investigate the mechanical properties and bonding characters of $\mathrm{Fe}_{80-\mathrm{x}} \mathrm{Ni}_{\mathrm{x}} \mathrm{P}_{13} \mathrm{C}_{7} \quad(\mathrm{x}=0,10,20,30)$ and $\mathrm{Fe}_{72-\mathrm{x}} \mathrm{Ni}_{\mathrm{x}} \mathrm{B}_{20} \mathrm{Si}_{4} \mathrm{Nb}_{4}(\mathrm{x}=0,7.2,14.4,21.6,28.8)$ BMGs. We also obtained X-ray photoelectron spectroscopy (XPS) and ultraviolet photoelectron spectroscopy (UPS) signatures to examine the change in bonding states during brittle to ductile transition in these Fe-based BMGs. Based on these results, we further derive that the plasticity versus brittleness properties of Fe-based BMGs can be understood essentially in terms of their distinctly different bonding natures. The derived conclusion provides a compelling approach to distinguish BMGs from an electronic structure point of view, and can be regarded as complementary to the common views focused on atomic configuration.

\section{Results}

Unprecedented plasticity of Fe-based BMGs. Figure 1 (a) shows the typical true stress-strain curves of as-cast $\mathrm{Fe}_{80-\mathrm{x}} \mathrm{Ni}_{\mathrm{x}} \mathrm{P}_{13} \mathrm{C}_{7}(\mathrm{x}=0,10$, 20 , 30) BMG rods with a diameter of $1.0 \mathrm{~mm}$ subjected to compressive deformation. It can be seen that the partial substitution of $\mathrm{Ni}$ for Fe dramatically enhances the plasticity of the $\mathrm{Fe}_{80} \mathrm{P}_{13} \mathrm{P}_{7} \quad \mathrm{BMG}$ and the $\mathrm{Fe}_{50} \mathrm{Ni}_{30} \mathrm{P}_{13} \mathrm{C}_{7}$ BMG rod exhibits unprecedented plasticity. It is generally considered that Fe-based BMGs are brittle at room temperature ${ }^{13,16}$. However, this measured compressive plastic strain value of $\mathrm{Fe}_{50} \mathrm{Ni}_{30} \mathrm{P}_{13} \mathrm{C}_{7}$ reaches as high as $22 \%$, which is extremely larger than those (normally less than $5 \%)^{10,13,15,16,28}$ for all the previously reported Fe-based BMGs. It is notable that the present plastic strain value even exceeds those of the typical ductile $\mathrm{Pt}_{57.5} \mathrm{Cu}_{14.7} \mathrm{Ni}_{5.3} \mathrm{P}_{22.5}$ (about 20\%) ${ }^{29}$ and $\mathrm{Cu}_{47.5} \mathrm{Zr}_{47.5} \mathrm{Al}_{5}$ (about $\left.18 \%\right)^{30}$ BMGs. As shown in the inset, the amplified section of $\mathrm{Fe}_{50} \mathrm{Ni}_{30} \mathrm{P}_{13} \mathrm{C}_{7}$ glassy stress-strain curve clearly shows strain-hardening characteristics in conjunction with serrated phenomenon, which is attributed to the unique structure correlated with atomic-scale inhomogeneity, leading to an inherent capability of extensive shear band formation, interactions, and multiplication of shear bands ${ }^{30}$. This kind of stress-strain curve behavior can be recognized only for ductile $\mathrm{BMGs}^{31}$. Specifically, under an applied bending load, the $\mathrm{Fe}_{50} \mathrm{Ni}_{30} \mathrm{P}_{13} \mathrm{C}_{7}$ BMG rod is capable of undergoing plastic bending in the absence of fracture as similar to flexible metals such as $\mathrm{Al}$ and $\mathrm{Cu}$, as shown in Fig. 1 (b). Previously, such unprecedented high plasticity and flexibility can be obtained only in supercooled liquid state of Fe-based BMGs at high temperatures ${ }^{32}$. The reproducibility of the mechanical properties in the present work is quite good, indicating that the $\mathrm{Fe}_{50} \mathrm{Ni}_{30} \mathrm{P}_{13} \mathrm{C}_{7}$ BMG with unprecedented plasticity is available as novel engineering materials.

The XRD and DSC traces obtained from the as-cast $\mathrm{Fe}_{50} \mathrm{Ni}_{30} \mathrm{P}_{13} \mathrm{C}_{7}$ BMG rod are also shown in Fig. 1 (c). The XRD pattern displays broad diffraction maxima, which is the characteristic of glassy structure. The DSC trace exhibits one endothermic event characteristic of the glass transition from glassy solid into supercooled liquid, followed by a crystallization exothermic reaction, which enables it to confirm the glassy nature of the alloy rod. Meanwhile, the HRTEM image and their corresponding selected area electron diffraction (SAED) pattern are shown in Fig. 1 (d). No crystalline phase appears in the HRTEM and the SAED pattern consists of a single diffraction halo without sharp diffraction rings. All these results confirm that the
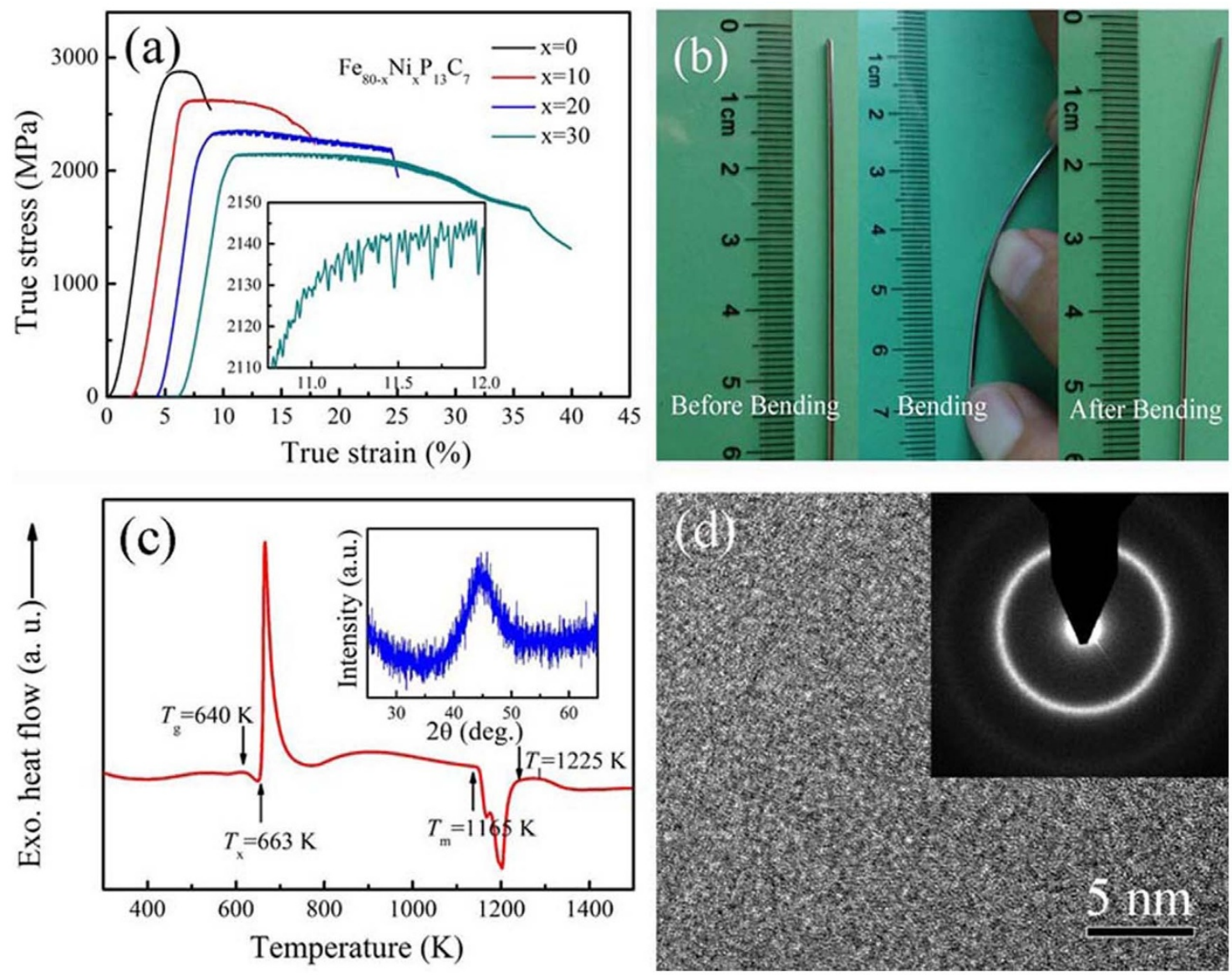

Figure $1 \mid$ (a) Compressive true stress-strain curves of $\mathrm{Fe}_{80-\mathrm{x}} \mathrm{Ni}_{\mathrm{x}} \mathrm{P}_{13} \mathrm{C}_{7}(\mathrm{x}=0,10,20,30) \mathrm{BMGs}$ at room temperature. The inset is the enlarged section of $\mathrm{Fe}_{50} \mathrm{Ni}_{30} \mathrm{P}_{13} \mathrm{C}_{7}$ BMG. (b) The images of a plastically bent $\mathrm{Fe}_{50} \mathrm{Ni}_{30} \mathrm{P}_{13} \mathrm{C}_{7}$ BMG rod with $1 \mathrm{~mm}$ diameter. (c) XRD and DSC traces of as-cast $\mathrm{Fe}_{50} \mathrm{Ni}_{30} \mathrm{P}_{13} \mathrm{C}_{7}$ glassy rod. (d) HRTEM image of the $\mathrm{Fe}_{50} \mathrm{Ni}_{30} \mathrm{P}_{13} \mathrm{C}_{7}$ glassy rod. The inset is the related SAED pattern. 

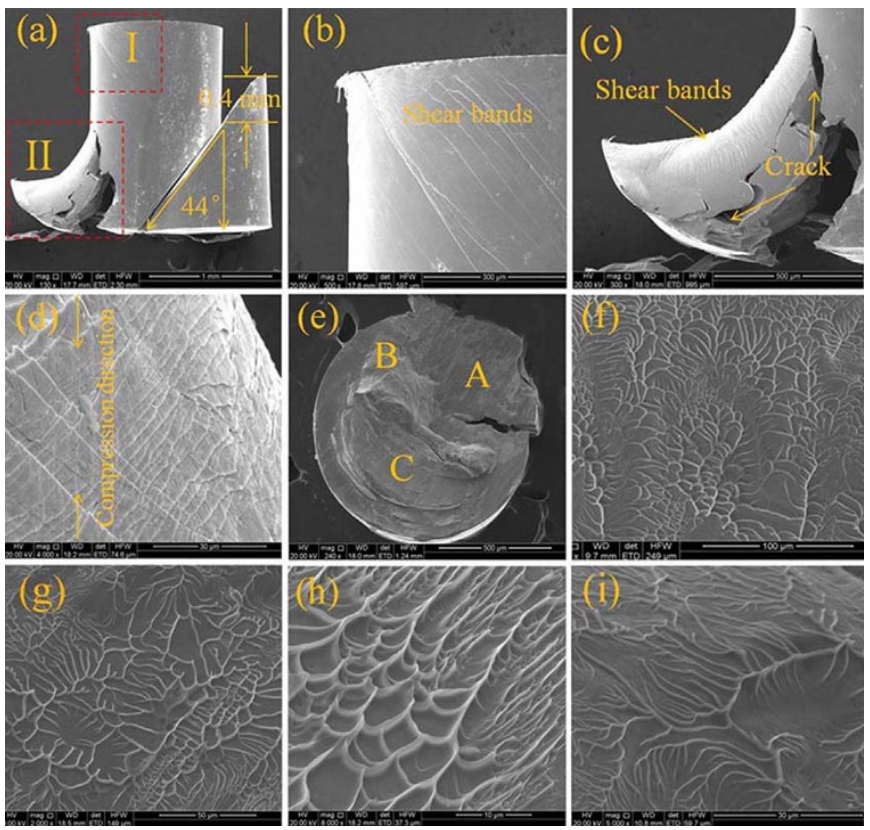

Figure $2 \mid$ (a) SEM image showing the $\mathrm{Fe}_{50} \mathrm{Ni}_{30} \mathrm{P}_{13} \mathrm{C}_{7}$ glassy rod which was unloaded before failure in compression. (b) and (c) Micrographs of high magnification showing regions I and II in (a), respectively. (d) SEM side-view images of another compression specimen. (e) SEM observation of the fracture features for $\mathrm{Fe}_{50} \mathrm{Ni}_{30} \mathrm{P}_{13} \mathrm{C}_{7}$ glassy rod after failure. (e) Top view; ( $\mathrm{f}$ ) and (g) are the enlarged fracture features of the A and B in (e), respectively; (h) and (i) are the magnifications of vein patterns.

rod specimens are composed of a fully glassy structure, and the concept of composites can be excluded from the causes of the unprecedented plasticity.

The morphology of $\mathrm{Fe}_{50} \mathbf{N i}_{30} \mathbf{P}_{13} \mathrm{C}_{7}$ BMG. Figure 2 shows SEM images of the $\mathrm{Fe}_{50} \mathrm{Ni}_{30} \mathrm{P}_{13} \mathrm{C}_{7}$ surface prior to failure subjected to compression test. Localized main shear bands appear in a nearelliptical morphology and end up at the sample side, which are characterized by a shear angle of about $44^{\circ}$ to the compressive axis [see Fig. 2 (a)]. The longitudinal slip distance is around $0.4 \mathrm{~mm}$, being consistent well with the plastic strain $(>20 \%)$ in the stressstrain curve. As can be seen in Fig. 2 (b), the enlarged region I exhibits an obvious shear-deformation-induced slip in the compressive specimen. Around the existing primary shear band [enlarged region II, see Fig. 2 (c)], it is noted that several remarkable cracks and scattered shear bands are emerged. The spontaneous formation of such cracks without instable propagation gives us a hint that the $\mathrm{Fe}_{50} \mathrm{Ni}_{30} \mathrm{P}_{13} \mathrm{C}_{7}$ BMG holds a definite resistance to the catastrophic failure. Meanwhile, quite uniform multiple shear bands are observed in the side-view SEM image of the same specimen, as shown in Fig. 2 (d). These shear bands are not straight in shape but rather interconnect or intersect with each other. Many small ledges, kinks, bifurcations, and branches along the shear bands can also be observed, indicating the high resistance ability to the propagation of shear bands.

We further examined the fracture surfaces of the $\mathrm{Fe}_{50} \mathrm{Ni}_{30} \mathrm{P}_{13} \mathrm{C}_{7}$ BMG rods. As shown in Fig. 2 (e), there are three distinguishable fracture morphologies: the shear plane of the main shear band (area $\mathrm{A})$; the basic cleavage surface (area $\mathrm{B}$ ); and the mirror-like region (area $\mathrm{C}$ ). In area A, the fracture surfaces show well-defined featherlike vein patterns with an average scale near $20 \mu \mathrm{m}$ [Fig. 2 (f)] and river-like vein patterns [Fig. 2 (g)]. The vein patterns often reflect the local viscous flow [Fig. 2 (h) and (i)] of the glassy metals and occur only in those BMGs with good malleability ${ }^{33}$. Applying the theory of plastic fracture to BMGs, the fracture toughness $K_{\mathrm{C}}$ can be estimated
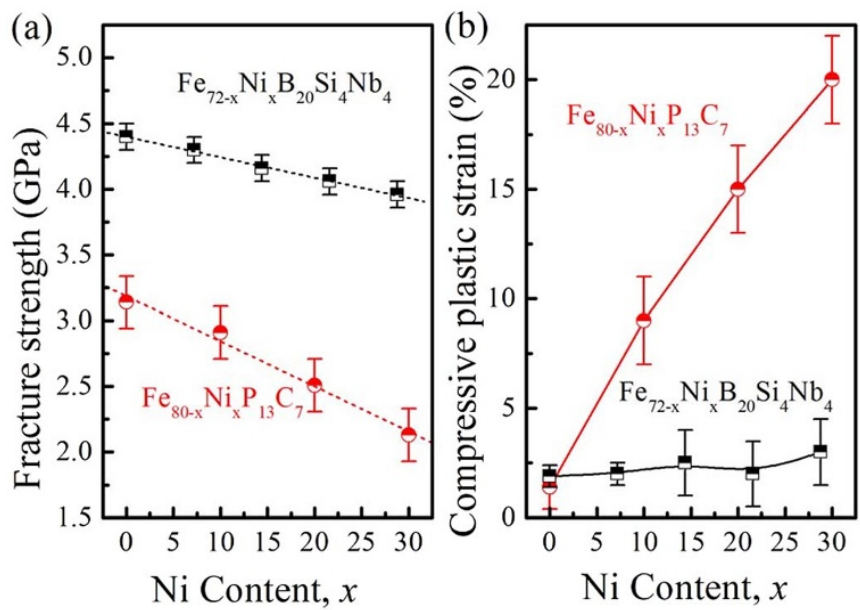

Figure 3 (a) Change in engineering fracture strength with $\mathrm{Ni}$ concentration for $\mathrm{Fe}_{80-\mathrm{x}} \mathrm{Ni}_{\mathrm{x}} \mathrm{P}_{13} \mathrm{C}_{7}$ and $\mathrm{Fe}_{72-\mathrm{x}} \mathrm{Ni}_{\mathrm{x}} \mathrm{B}_{20} \mathrm{Si}_{4} \mathrm{Nb}_{4}$ BMGs. (b) Change in compressive plasticity with $\mathrm{Ni}$ concentration for $\mathrm{Fe}_{80-\mathrm{x}} \mathrm{Ni}_{\mathrm{x}} \mathrm{P}_{13} \mathrm{C}_{7}$ and $\mathrm{Fe}_{72-\mathrm{x}} \mathrm{Ni}_{\mathrm{x}} \mathrm{B}_{20} \mathrm{Si}_{4} \mathrm{Nb}_{4}$ BMGs.

using $r_{\mathrm{p}}=(1 / 6 \pi)\left(K_{\mathrm{C}} / \sigma_{y}\right)^{2}$, where $r_{\mathrm{p}}$ is the plastic zone area size and $\sigma_{y}$ is the yield strength ${ }^{3}$. The values of $r_{\mathrm{p}}$ and $\sigma_{y}$ for the $\mathrm{Fe}_{50} \mathrm{Ni}_{30} \mathrm{P}_{13} \mathrm{C}_{7}$ BMG are around $20 \mu \mathrm{m}$ and $2250 \mathrm{MPa}$, respectively, thus the $K_{\mathrm{C}}$ is calculated to be nearly $50 \mathrm{MPa} \cdot \mathrm{m}^{1 / 2}$, which is much larger than that of previous reported Fe-based BMGs ${ }^{14,34}$.

The deformation behavior comparison of Fe-based BMGs. In order to understand the deformation behavior of $\mathrm{Fe}_{80-\mathrm{x}} \mathrm{Ni}_{\mathrm{x}} \mathrm{P}_{13} \mathrm{C}_{7}$ and $\mathrm{Fe}_{72-\mathrm{x}} \mathrm{Ni}_{\mathrm{x}} \mathrm{B}_{20} \mathrm{Si}_{4} \mathrm{Nb}_{4}$ BMGs, typical mechanical properties of engineering fracture strength and compressive plastic strain have been compared by adjusting the Ni content. As shown in Fig. 3 (a), the strength decreases monotonically with increasing Ni content for both BMG systems. Although the value of plastic strains in the precursor alloys $\mathrm{Fe}_{72} \mathrm{~B}_{20} \mathrm{Si}_{4} \mathrm{Nb}_{4}(\sim 2 \%)$ and $\mathrm{Fe}_{80} \mathrm{P}_{13} \mathrm{C}_{7}(\sim 1.5 \%)$ is similar, it increases significantly from $1.5 \%$ to $22 \%$ with $\mathrm{Ni}$ addition in $\mathrm{Fe}_{80-\mathrm{x}} \mathrm{Ni}_{\mathrm{x}} \mathrm{P}_{13} \mathrm{C}_{7}$ system, while the plastic strain in $\mathrm{Fe}_{72-\mathrm{x}} \mathrm{Ni}_{\mathrm{x}} \mathrm{B}_{20} \mathrm{Si}_{4} \mathrm{Nb}_{4}$ system seems to be independent to the $\mathrm{Ni}$ content, as shown in Fig. 3 (b).

\section{Discussion}

It is believed that the interatomic bonds in atomic configurations contribute to the flexibility or mobility of BMGs, which controls the intrinsic plasticity versus brittleness properties ${ }^{26,35}$. The characteristic of interatomic bonds is essentially determined by the valence electrons $(d, p \text {, and } s)^{26}$. The $s$ electrons are delocalized while the $d$ electrons are highly localized. Two possible charge densities exist around the atoms in BMGs: One is expected if the valence electrons of atomic bonds are $p$ - $d$ hybrid electrons, and the other is expected in bonds with only valence $s$ electrons ${ }^{36}$. Since the strength and plasticity of the bonds in BMGs are related to the amount of charge in the overlap region of the atomic orbitals, the absence of charge polarization will require more energy to shear the atoms. Therefore, the ductile metal-metal bonds imply more $s$ wave function participation in the bonding and high degrees of bond mobility ${ }^{37}$. For metal-metalloid bonds, the $p$ electrons could transfer from the metalloid elements and fill the $d$ shells of transition metal, leading finally to the formation of $p$ - $d$ hybrid bonding ${ }^{38}$. The $p$ - $d$ hybrid bonds are strong covalent and thus should resist shear while the $s$-like bonds are relatively weak and thus more easily accommodate shear. Hence, BMGs are expected to exhibit ductile nature if the electronic configuration becomes mostly $s$-like and has more likely uniform valence charge density, because the bonding in this case will be more nondirectional ${ }^{27}$. In other words, during the shear moving of atoms, the $p$ - $d$ hybrid bonds are more prone to broke due to the obvious change 
(a)

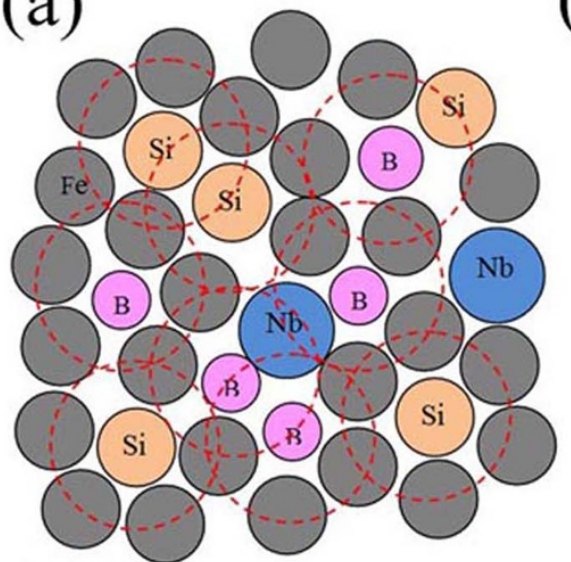

(c)

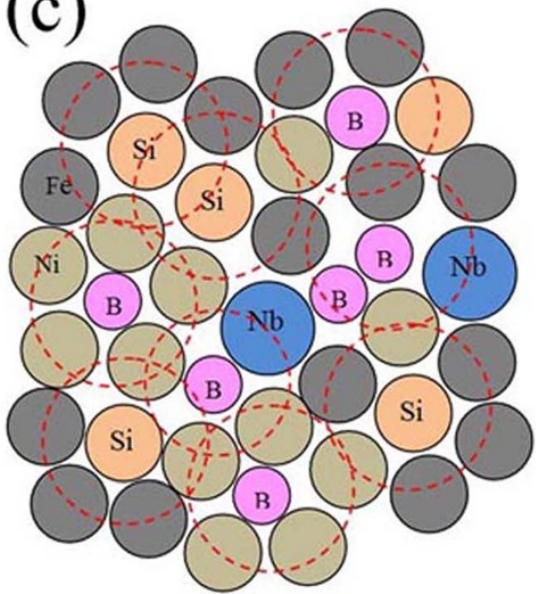

(b)

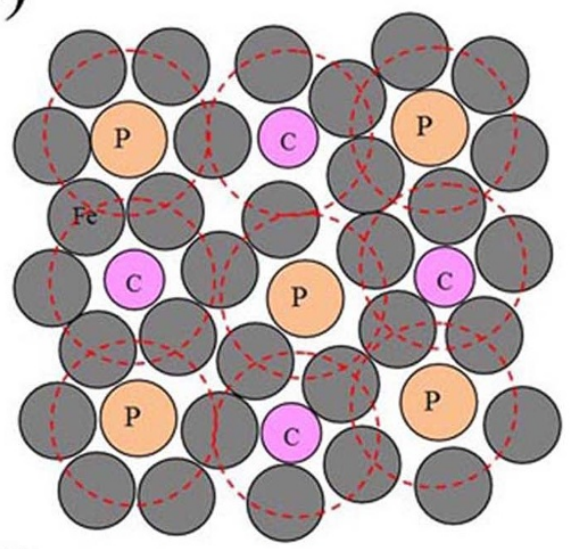

(d)

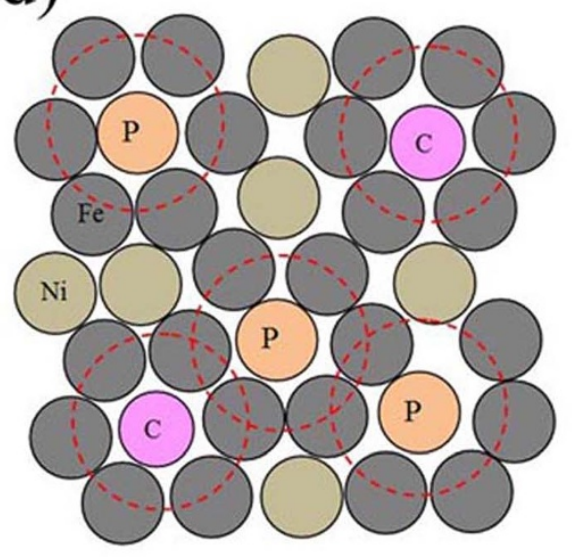

Figure $4 \mid$ Schematic illustrations for the structure of Fe-(Ni)-B-Si-Nb and Fe-(Ni)-P-C BMGs. The purple dashed circles indicate clusters.

of atomic orbital overlap, while non-directional $s$ character bonds with good mobility can absorb more energy at crack tip as atoms can yield long distance, dissipate larger amount of fracture energy and exhibit more plasticity. The bonds resulted from the overlap of $p-d$ electrons have directionality and are localized in particular bonds. When the BMG is stressed, the electrons remain localized until the stress is sufficient enough to expel them from a bond. Hence, rather than a smooth response to stress, the BMG behaves discontinuously as each bond is broken. As the BMGs are deformed, the bonding charge flows smoothly in and out, allowing the electrons to hop across bond to bond, which introduces high ductility in this kind of BMGs. In sum, the metal-metalloid bonds are strongly covalent and thus could resist shear, while the metal-metal bonds are weakened and thus more easily accommodate shear.

The completely different trend in plastic strain with Ni substitution in $\mathrm{Fe}_{80-\mathrm{x}} \mathrm{Ni}_{\mathrm{x}} \mathrm{P}_{13} \mathrm{C}_{7}$ and $\mathrm{Fe}_{72-\mathrm{x}} \mathrm{Ni}_{\mathrm{x}} \mathrm{B}_{20} \mathrm{Si}_{4} \mathrm{Nb}_{4}$ systems is investigated on the basis of their atomic configurations. The fundamental building blocks are solute-centered clusters rather than individual atoms, with solute or minor atoms at the center surrounded by solvent or majority atoms in $\mathrm{BMGs}^{24,25,39}$. The B-centered prism-like clusters are embedded in a bcc-like $\mathrm{Fe}-\mathrm{Si}$ solid solution ${ }^{40}$ in $\mathrm{Fe}-\mathrm{Si}$ $\mathrm{B}-\mathrm{Nb}$ system, as shown in Fig. 4 (a). However, the P-centered antiprism-like and C-centered prism-like clusters are embedded in Fe-P-C system ${ }^{40}$, as shown in Fig. 4 (b). For the present systems, the B atom at a local level has a stronger interaction with $\mathrm{Ni}$ atoms than with $\mathrm{Fe}$ atoms, whereas $\mathrm{P}$ atom has a stronger interaction with $\mathrm{Fe}$ atoms than with $\mathrm{Ni}$ atoms, as pointed by Messmer ${ }^{41}$. As indicated by their enthalpy values of mixing ${ }^{42}$, the bonds of $\mathrm{Ni}-\mathrm{Si}(-40 \mathrm{~kJ} / \mathrm{mol})$ and $\mathrm{Ni}-\mathrm{Nb}(-30 \mathrm{~kJ} / \mathrm{mol})$ in $\mathrm{Fe}_{72-\mathrm{x}} \mathrm{Ni}_{\mathrm{x}} \mathrm{B}_{20} \mathrm{Si}_{4} \mathrm{Nb}_{4}$ are also stronger than those of $\mathrm{Fe}-\mathrm{Si}(-35 \mathrm{~kJ} / \mathrm{mol})$ and $\mathrm{Fe}-\mathrm{Nb}(-16 \mathrm{~kJ} / \mathrm{mol})$. Therefore, the atomic configurations in $\mathrm{Fe}_{72} \mathrm{~B}_{20} \mathrm{Si}_{4} \mathrm{Nb}_{4}$ system have no obvious change with increasing Ni content, as illustrated in Fig. 4 (c). The presences of $\mathrm{B}$ and $\mathrm{Si}$ elements in $\mathrm{Fe}_{72-\mathrm{x}} \mathrm{Ni}_{\mathrm{x}} \mathrm{B}_{20} \mathrm{Si}_{4} \mathrm{Nb}_{4}$ system still keep the covalent character of the bonds and absence of mobility. Under applied stress, the bonds no longer slide smoothly and tend to break apart. However, in $\mathrm{Fe}_{80-\mathrm{x}} \mathrm{Ni}_{\mathrm{x}} \mathrm{P}_{13} \mathrm{C}_{7}$ system, the enthalpy values of mixing of Ni-P $(-34.5 \mathrm{~kJ} / \mathrm{mol})$ and Ni-C $(-39 \mathrm{~kJ} / \mathrm{mol})$ are much smaller than those of Fe-P $(-39.5 \mathrm{~kJ} / \mathrm{mol})$ and $\mathrm{Fe}-\mathrm{C}(-50 \mathrm{~kJ} / \mathrm{mol})$. As a result, the Ni atoms might break away from the $\mathrm{P}$ and $\mathrm{C}$-centered clusters, the $\mathrm{P}$-centered antiprism-like and $\mathrm{C}$-centered prismlike clusters can be embedded in $\mathrm{Fe}_{80-\mathrm{x}} \mathrm{Ni}_{\mathrm{x}} \mathrm{P}_{13} \mathrm{C}_{7}$ system, as illustrated in Fig. 4 (d). In this system, metalloid atoms do not occupy the nearest-neighbor site, and the regions between clusters are empty or occupied by $\mathrm{Ni}$ atoms. As the Ni content increasing, the amount of metal-metal bonds linking the clusters becomes more and more. The less directional metal-metal bonds enable easily accommodation of shear strain and absorption energy in the front of crack tip. Therefore, different from the $\mathrm{Fe}_{72-\mathrm{x}} \mathrm{Ni}_{\mathrm{x}} \mathrm{B}_{20} \mathrm{Si}_{4} \mathrm{Nb}_{4}$ system, the plastic strain of $\mathrm{Fe}_{80-\mathrm{x}} \mathrm{Ni}_{\mathrm{x}} \mathrm{P}_{13} \mathrm{C}_{7}$ system is obviously enhanced with adding $\mathrm{Ni}$, while the strength of $\mathrm{Fe}_{80-\mathrm{x}} \mathrm{Ni}_{\mathrm{x}} \mathrm{P}_{13} \mathrm{C}_{7}$ system is lower than that of $\mathrm{Fe}_{72-\mathrm{x}} \mathrm{Ni}_{\mathrm{x}} \mathrm{B}_{20} \mathrm{Si}_{4} \mathrm{Nb}_{4}$ glassy system.

Above conclusions were further verified by analyzing the density of states (DOS) of valence electrons in BMGs. We obtained the XPS and UPS spectra of $\mathrm{Fe}_{80-\mathrm{x}} \mathrm{Ni}_{\mathrm{x}} \mathrm{P}_{13} \mathrm{C}_{7}$ and $\mathrm{Fe}_{72-\mathrm{x}} \mathrm{Ni}_{\mathrm{x}} \mathrm{B}_{20} \mathrm{Si}_{4} \mathrm{Nb}_{4}$ glassy systems. In order to get at least relative information about the DOS, the spectra were normalized in such a way that the ratio of the areas below the curves is proportional to the total number of valence electrons $(d, p \text { and } s)^{43}$. This procedure was carried out after 




Figure $5 \mid$ (a) XPS valence-band spectrum for $\mathrm{Fe}_{80-\mathrm{x}} \mathrm{Ni}_{\mathrm{x}} \mathrm{P}_{13} \mathrm{C}_{7}$ BMGs. (b) XPS valence-band spectrum for $\mathrm{Fe}_{72-\mathrm{x}} \mathrm{Ni}_{\mathrm{x}} \mathrm{B}_{20} \mathrm{Si}_{4} \mathrm{Nb}_{4}$ BMGs. (c) UPS valence-band spectrum for $\mathrm{Fe}_{80-\mathrm{x}} \mathrm{Ni}_{\mathrm{x}} \mathrm{P}_{13} \mathrm{C}_{7}$ BMGs. (d) UPS valence-band spectrum for $\mathrm{Fe}_{72-\mathrm{x}} \mathrm{Ni}_{\mathrm{x}} \mathrm{B}_{20} \mathrm{Si}_{4} \mathrm{Nb}_{4}$ BMGs.

a background subtraction. The positions of the Fermi level $\left(E_{\mathrm{F}}\right)$ are indicated by the vertical dotted lines, as seen in Fig. 5. For $\mathrm{Fe}_{80-\mathrm{x}} \mathrm{Ni}_{\mathrm{x}} \mathrm{P}_{13} \mathrm{C}_{7}$ glassy system, the spectra show noticeable peaks, which shift from $1.30 \mathrm{eV}$ to $1.62 \mathrm{eV}$, and the peaks become more and more pronounced when they shift to higher binding energy with $\mathrm{Fe}$ replacing by $\mathrm{Ni}$, as shown in Fig. 5 (a). However, the peaks have no obvious difference with $\mathrm{Ni}$ content addition in $\mathrm{Fe}_{72-\mathrm{x}} \mathrm{Ni}_{\mathrm{x}} \mathrm{B}_{20} \mathrm{Si}_{4} \mathrm{Nb}_{4}$ system, as shown in Fig. 5 (b). Similarly, the UPS spectra of $\mathrm{Fe}_{80-\mathrm{x}} \mathrm{Ni}_{\mathrm{x}} \mathrm{P}_{13} \mathrm{C}_{7}$ and $\mathrm{Fe}_{72-\mathrm{x}} \mathrm{Ni}_{\mathrm{x}} \mathrm{B}_{20} \mathrm{Si}_{4} \mathrm{Nb}_{4}$ glassy alloys are also shown in Fig. 5 (c) and (d). Comparing with Fig. 5 (c) and (d), we can see that the DOS of $\mathrm{Fe}_{80-\mathrm{x}} \mathrm{Ni}_{\mathrm{x}} \mathrm{P}_{13} \mathrm{C}_{7}$ alloys near $E_{\mathrm{F}}$ is more distinctly reduced than that of $\mathrm{Fe}_{72-\mathrm{x}} \mathrm{Ni}_{\mathrm{x}} \mathrm{B}_{20} \mathrm{Si}_{4} \mathrm{Nb}_{4}$ glassy alloys as $\mathrm{Ni}$ content increases. This means the decreasing Ni content for $\mathrm{Fe}_{80-\mathrm{x}} \mathrm{Ni}_{\mathrm{x}} \mathrm{P}_{13} \mathrm{C}_{7}$ alloys contributes to the DOS of $p-d$ hybridization at $E_{\mathrm{F}}$, while no obvious change is introduced for the corresponding $\mathrm{Fe}_{72-\mathrm{x}} \mathrm{Ni}_{\mathrm{x}} \mathrm{B}_{20} \mathrm{Si}_{4} \mathrm{Nb}_{4}$ system. The weak $p$ - $d$ hybridization is responsible for high $s$ DOS near the $E_{\mathrm{F}}^{44}$. In the ductile glassy alloys, it has been verified that the $p$ - $d$ hybridization lies well below the $E_{\mathrm{F}}$. On the contrary, the $p$ - $d$ hybridization in brittle MGs is located exactly at the $E_{\mathrm{F}}$. The XPS and UPS experimental spectra are in agreement with the above-described analysis. Furthermore, the binding energy of Fe $3 d$ states is about $1.0 \mathrm{eV}$, and that of $\mathrm{Ni} 3 d$ states is about $2.0 \mathrm{eV}^{45}$. The peak shift from the character of $p$ - $d$ hybridization to $\mathrm{Ni}-\mathrm{Ni}$ bonds for the $\mathrm{Fe}_{80-\mathrm{x}} \mathrm{Ni}_{\mathrm{x}} \mathrm{P}_{13} \mathrm{C}_{7}$ alloys indicates that the $\mathrm{Ni}-\mathrm{Ni}$ bonds become more pronounced as the Ni content increases. To summarize, from the perspective of chemical effects, a high Ni environment would suppress the $p-d$ electron interaction between transition metal and nonmetallic atoms $(\mathrm{P}$ or $\mathrm{C})$, reduce the covalent-like character of the bonding, and thus elevate the plasticity. These results confirm that the clusters in the ductile Fe-Ni-P-C BMGs are mainly connected with metal-metal bonds, and the clusters in the brittle $\mathrm{Fe}-\mathrm{Ni}-\mathrm{B}-\mathrm{Si}-\mathrm{Nb}$ BMGs are connected with metal-metalloid bonds through vertice-, edge- and face-shared modes of the constituent atoms.

The bonding character also can be quantified by the study of charge transfer ${ }^{36}$, which can be assessed through the magnetic properties in ferromagnetic $\mathrm{BMGs}^{38}$. Figure 6 shows the comparisons of the magnetic properties of $\mathrm{Fe}_{80-\mathrm{x}} \mathrm{Ni}_{\mathrm{x}} \mathrm{P}_{13} \mathrm{C}_{7}$ and $\mathrm{Fe}_{72-\mathrm{x}} \mathrm{Ni}_{\mathrm{x}} \mathrm{B}_{20} \mathrm{Si}_{4} \mathrm{Nb}_{4}$ glassy systems. The saturation magnetization as a function of $\mathrm{Ni}$ content is shown in Fig. 6 (a). We can see that the saturation magnetization decreases monotonically with increasing $\mathrm{Ni}$ content for both $\mathrm{Fe}_{80-\mathrm{x}} \mathrm{Ni}_{\mathrm{x}} \mathrm{P}_{13} \mathrm{C}_{7}$ and $\mathrm{Fe}_{72-\mathrm{x}} \mathrm{Ni}_{\mathrm{x}} \mathrm{B}_{20} \mathrm{Si}_{4} \mathrm{Nb}_{4}$ alloys ${ }^{28,46}$. Fig. 6 (b) shows the corresponding Curie temperature as a function of $\mathrm{Ni}$
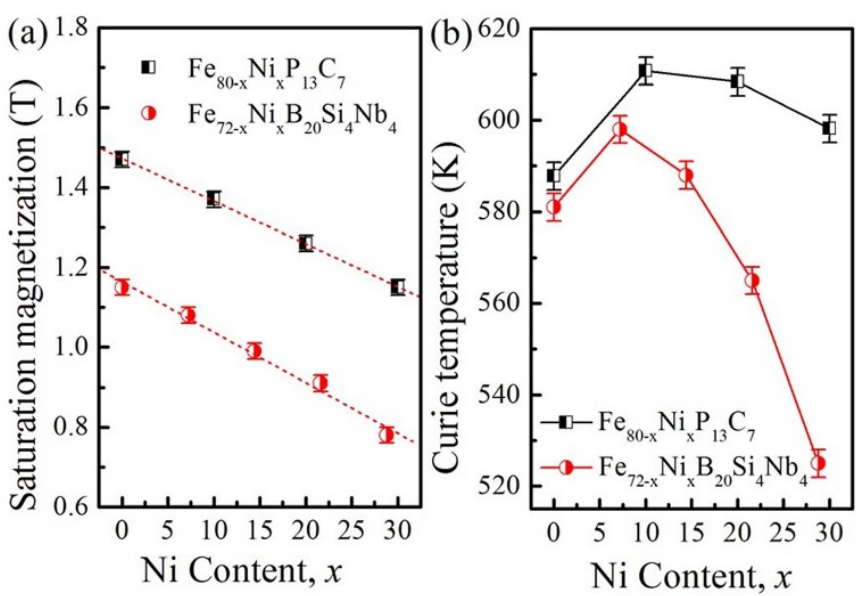

Figure 6 (a) Change in saturation magnetization with Ni concentration for $\mathrm{Fe}_{80-\mathrm{x}} \mathrm{Ni}_{\mathrm{x}} \mathrm{P}_{13} \mathrm{C}_{7}$ and $\mathrm{Fe}_{72-\mathrm{x}} \mathrm{Ni}_{\mathrm{x}} \mathrm{B}_{20} \mathrm{Si}_{4} \mathrm{Nb}_{4}$ BMGs. (b) Change in Curie temperature with $\mathrm{Ni}$ concentration for $\mathrm{Fe}_{80-\mathrm{x}} \mathrm{Ni}_{\mathrm{x}} \mathrm{P}_{13} \mathrm{C}_{7}$ and $\mathrm{Fe}_{72-\mathrm{x}} \mathrm{Ni}_{\mathrm{x}} \mathrm{B}_{20} \mathrm{Si}_{4} \mathrm{Nb}_{4}$ BMGs.

composition in these systems. The Curie temperature increases through a broad maximum at $x=7.2$ for the $\mathrm{Fe}_{72-\mathrm{x}} \mathrm{Ni}_{\mathrm{x}} \mathrm{B}_{20} \mathrm{Si}_{4} \mathrm{Nb}_{4}$ series and then decreases dramatically as $x$ increases. In $\mathrm{Fe}_{80-\mathrm{x}} \mathrm{Ni}_{\mathrm{x}} \mathrm{P}_{13} \mathrm{C}_{7}$ system, the Curie temperature also goes through a broad maximum, but decreases slowly as $x$ increases. Curie temperature of ferromagnetic BMGs can be expressed as ${ }^{47}$

$$
T_{\mathrm{C}}=(1-x) 2 S(S+1) \frac{1}{3 k_{\mathrm{B}}}\left[8 J_{\mathrm{d}}(x)+\sum_{n=1}^{6} Z_{n} J_{\mathrm{n}}(x)\right]
$$

where $S$ is spin moment, $k_{\mathrm{B}}$ the Boltzmann's constant, $J_{\mathrm{d}}$ the exchange interaction by $3 d$ electrons, $Z_{\mathrm{n}}$ the number of atoms in the $n$th $n . n$. shell, and $J_{\mathrm{n}}$ the indirect interaction between $n$th $n . n$. spins; its concentration dependence arises because $s$ electron density of the alloy changes with solute and/or solvent concentration and valence. The $J_{\mathrm{d}}$ affected by $3 d$ localization electrons can only be interacted in one atomic distance, whereas the $J_{\mathrm{n}}$ affected by $s$ nonlocalization electrons can be interacted in six atomic distances. It is known that the number of holes in the down-spin band of $3 d$ metal atoms is primarily determined by the number of the nearest neighbor atoms. Here, the numbers of $3 d$ band electrons for Fe and Ni elements are 6 and 8 , respectively. In both systems, the $J_{\mathrm{d}}$ decreases with increasing $\mathrm{Ni}$ content in a similar way ${ }^{46}$. Thus, it is concluded that $J_{\mathrm{n}}$ by $s$ electrons increases with increasing $\mathrm{Ni}$ content, especially in the $\mathrm{Fe}_{80-\mathrm{x}} \mathrm{Ni}_{\mathrm{x}} \mathrm{P}_{13} \mathrm{C}_{7}$ system. Also, it indicates more $s$ electrons would change into bonding states and thus strongly participates in bonding in $\mathrm{Fe}_{80-\mathrm{x}} \mathrm{Ni}_{\mathrm{x}} \mathrm{P}_{13} \mathrm{C}_{7}$ system with $\mathrm{Ni}$ addition, which consists well with above analysis.

In summary, an unprecedented plasticity was obtained for the $\mathrm{Fe}_{50} \mathrm{Ni}_{30} \mathrm{P}_{13} \mathrm{C}_{7}$ BMG. The plasticity is attributed to the nucleation and formation of multiple and homogeneous distributed shear bands throughout the whole BMG due to its unique atomic configuration. It is suggested Fe-based BMGs with large plasticity are formed when the clusters are linked with metal-metal bonds that exhibit high degrees of bond mobility and the shear bands are easily accommodated. The XPS and UPS results are consistent with the observed deformation behaviors of the present Fe-based BMGs. The present knowledge gives us a guideline for future syntheses of tough Fe-based BMGs which have high potential of commercial applications.

\section{Methods}

The $\mathrm{Fe}_{80-\mathrm{x}} \mathrm{Ni}_{\mathrm{x}} \mathrm{P}_{13} \mathrm{C}_{7}$ and $\mathrm{Fe}_{72-\mathrm{x}} \mathrm{Ni}_{\mathrm{x}} \mathrm{B}_{20} \mathrm{Si}_{4} \mathrm{Nb}_{4}$ BMGs with a diameter of $1.0 \mathrm{~mm}$ were prepared by water quenching and copper mold casting, respectively. The nature of glassy samples was ascertained by $\mathrm{D} 8$ Advance X-ray diffraction (XRD) with $\mathrm{Cu} \mathrm{K} \alpha$ radiation, NETZSCH DSC-404 differential scanning calorimetry (DSC) with a 
heating rate of $0.67 \mathrm{~K} / \mathrm{s}$, and high resolution transmission electron microscopy (HRTEM) using a Tecnai F20 microscope.

The specimens for compression test were cut out from the as-cast rods, and each end was polished to make it parallel to each other prior to the compression test. The mechanical behavior of at least 10 as-cast samples with a diameter of $1.0 \mathrm{~mm}$ and an aspect ratio of $2: 1$ was examined under uniaxial compression using an Instron testing machine at room temperature, and the strain rate was $5 \times 10^{-4} \mathrm{~s}^{-1}$. The tests were carried out in a constant-crosshead-displacement-rate controlled manner. The lateral and fracture surface morphologies were examined by scanning electron microscopy (SEM).

The bonding states were evaluated by XPS using a Kratos AXIS ULTRA ${ }^{\text {DLD }}$ instrument with a monochromic $\mathrm{Al} \mathrm{K}_{\alpha} \mathrm{X}$-ray source $(h v=1486.6 \mathrm{eV})$. The power was $120 \mathrm{~W}$ and the X-ray spot size was set to be $700 \times 300 \mu \mathrm{m}$. The pass energy of the XPS analyzer was set at $20 \mathrm{eV}$. The base pressure of the analysis chamber was better than $5 \times 10^{-9}$ Torr. All spectra were calibrated using the binding energy (BE) of C $1 \mathrm{~s}$ $(284.8 \mathrm{eV})$ as a reference, ultraviolet source (He I $21.2 \mathrm{eV}$ and He II $40.8 \mathrm{eV}$ ) and etching condition (beam energy $2 \mathrm{kV}$, extractor current $100 \mu \mathrm{A}$,raster size $4 \mathrm{~mm}$ ).

1. Inoue, A., Shinohara, Y. \& Gook, J. S. Thermal and magnetic properties of bulk Febased glassy alloys prepared by copper mold casting. Mater. Trans.-JIM 36, 1427-1433 (1995).

2. Wang, J. Q. et al. Rapid degradation of azo dye by Fe-based metallic glass powder. Adv. Funct. Mater. 22, 2567-2570 (2012).

3. Xi, X. et al. Fracture of brittle metallic glasses: Brittleness or plasticity. Phys. Rev. Lett. 94, 125501 (2005).

4. Wang, G. et al. Nanoscale periodic morphologies on the fracture surface of brittle metallic glasses. Phys. Rev. Lett. 98, 235501 (2007).

5. Suryanarayana, C. \& Inoue, A. Iron-based bulk metallic glasses. Int. Mater. Rev. 58, 131-166 (2013).

6. Shen, B., Akiba, M. \& Inoue, A. Effects of Si and Mo additions on glass-forming in FeGaPCB bulk glassy alloys with high saturation magnetization. Phys. Rev. B 73, 104204 (2006).

7. Lu, Z., Liu, C., Thompson, J. \& Porter, W. Structural amorphous steels. Phys. Rev. Lett. 92, 245503 (2004)

8. Gao, J. E. et al. Fe-based bulk metallic glass composites without any metalloid elements. Acta Mater. 61, 3214-3223 (2013).

9. Li, H. X. et al. Enhancing glass-forming ability via frustration of nano-clustering in alloys with a high solvent content. Sci. Rep. 3, 1983 (2013).

10. Gu, X. J., Poon, S. J., Shiflet, G. J. \& Widom, M. Ductility improvement of amorphous steels: Roles of shear modulus and electronic structure. Acta Mater. 56, 88-94 (2008).

11. Chang, C., Shen, B. \& Inoue, A. FeNi-based bulk glassy alloys with superhigh mechanical strength and excellent soft-magnetic properties. Appl. Phys. Lett. 89, 051912 (2006)

12. Yao, J. H., Wang, J. Q. \& Li, Y. Ductile Fe-Nb-B bulk metallic glass with ultrahigh strength. Appl. Phys. Lett. 92, 251906 (2008).

13. Park, J. M. et al. Enhancement of plastic deformability in Fe-Ni-Nb-B bulk glassy alloys by controlling the Ni-to-Fe concentration ratio. Appl. Phys. Lett. 96, 031905 (2010).

14. Guo, S. F., Li, N., Zhang, C. \& Liu, L. Enhancement of plasticity of Fe-based bulk metallic glass by Ni substitution for Fe. J. Alloys Compd. 504, S78-S81 (2010).

15. Seifoddini, A. et al. New $\left(\mathrm{Fe}_{0.9} \mathrm{Ni}_{0.1}\right)_{77} \mathrm{Mo}_{5} \mathrm{P}_{9} \mathrm{C}_{7.5} \mathrm{~B}_{1.5}$ glassy alloys with enhanced glass-forming ability and large compressive strain. Mater. Sci. Eng. A 560, 575-582 (2013).

16. Yao, K. F. \& Zhang, C. Q. Fe-based bulk metallic glass with high plasticity. Appl. Phys. Lett. 90, 061901 (2007).

17. Duscher, G., Chisholm, M. F., Alber, U. \& Ruhle, M. Bismuth-induced embrittlement of copper grain boundaries. Nat. Mater. 3, 621-626 (2004).

18. Wang, G. et al. Evolution of nanoscale morphology on fracture surface of brittle metallic glass. Appl. Phys. Lett. 89, 121909 (2006).

19. Hays, C. C., Kim, C. P. \& Johnson, W. L. Microstructure controlled shear band pattern formation and enhanced plasticity of bulk metallic glasses containing in situ formed ductile phase dendrite dispersions. Phys. Rev. Lett. 84, 2901-2904 (2000)

20. Sarac, B. \& Schroers, J. Designing tensile ductility in metallic glasses. Nat. Commun. 4, 1-7 (2013).

21. Liu, Y. H. et al. Super plastic bulk metallic glasses at room temperature. Science 315, 1385-1388 (2007)

22. Spaepen, F. A microscopic mechanism for steady state inhomogeneous flow in metallic glasses. Acta Mater. 55, 407-415 (1977).

23. Falk, M. L. \& Langer, J. S. Dynamics of viscoplastic deformation in amorphous solids. Phys. Rev. E 57, 7192-7205 (1998).

24. Miracle, D. B. A structural model for metallic glasses. Nat. Mater. 3, 697-702 (2004).

25. Sheng, H. W., Luo, W. K., Alamgir, F. M., Bai, J. M. \& Ma, E. Atomic packing and short-to-medium-range order in metallic glasses. Nature 439, 419-425 (2006).

26. Niu, H. et al. Extra-electron induced covalent strengthening and generalization of intrinsic ductile-to-brittle criterion. Sci. Rep. 2, 718 (2012).

27. Yuan, C. C., Xiang, J. F., Xi, X. K. \& Wang, W. H. NMR signature of evolution of ductile-to-brittle transition in bulk metallic glasses. Phys. Rev. Lett. 107, 236403 (2011).
28. Ma, X. H., Yang, X. H., Li, Q. \& Guo, S. F. Quaternary magnetic FeNiPC bulk metallic glasses with large plasticity. J. Alloys Compd. 577, 345-350 (2013).

29. Schroers, J. \& Johnson, W. L. Ductile bulk metallic glass. Phys. Rev. Lett. 93, 255506 (2004).

30. Das, J. et al. "Work-hardenable" ductile bulk metallic glass. Phys. Rev. Lett 94, 205501 (2005).

31. Sun, B. A. et al. Plasticity of ductile metallic glasses: A self-organized critical state Phys. Rev. Lett. 105, 035501 (2010).

32. Zhang, W., Fang, C. F. \& Li, Y. H. Ferromagnetic Fe-based bulk metallic glasses with high thermoplastic formability. Scr. Mater. 69, 77-80 (2013).

33. Inoue, A. Stabilization of metallic supercooled liquid and bulk amorphous alloys Acta Mater. 48, 279-306 (2000).

34. Shek, C. H., Lin, G. M., Lee, K. L. \& Lai, J. K. L. Fractal fracture of amorphous $\mathrm{Fe}_{46} \mathrm{Ni}_{32} \mathrm{~V}_{2} \mathrm{Si}_{14} \mathrm{~B}_{6}$ alloy. J. Non-Cryst. Solids 224, 244-248 (1998).

35. Haydock, R. The mobility of bonds at metal surfaces (heterogeneous catalysis). J. Phys. C: Solid State Phys. 14, 3807-3816 (1981).

36. Eberhart, M. E., Latanision, R. M. \& Johnson, K. H. The chemistry of fracture: A basis for analysis. Acta Mater. 33, 1769-1783 (1985).

37. Gschneidner Jr, K. A. et al. Influence of the electronic structure on the ductile behavior of B2 CsCl-type AB intermetallics. Acta Mater. 57, 5876-5881 (2009).

38. Yamauchi, K. \& Mizoguchi, T. The magnetic moments of amorphous metalmetalloid alloys. J. Phys. Soc. Japan. 39, 541-542 (1975).

39. Ma, D., Stoica, A. D. \& Wang, X. L. Power-law scaling and fractal nature of medium-range order in metallic glasses. Nat. Mater. 8, 30-34 (2009).

40. Zhou, S. X. et al. The relationship between the stability of glass-forming Fe-based liquid alloys and the metalloid-centered clusters. J. Appl. Phys. 112, 023514 (2012).

41. Messmer, R. Local electronic structure of amorphous metal alloys using cluster models. Evidence for specific metalloid-metal interactions. Phys. Rev. B 23, 1616-1623 (1981).

42. Takeuchi, A. \& Inoue, A. Classification of bulk metallic glasses by atomic size difference, heat of mixing and period of constituent elements and its application to characterization of the main alloying element. Mater. Trans. 46, 2817-2829 (2005).

43. Oelhafen, P., Hauser, E., Güntherodt, H. \& Bennemann, K. New type of d-bandmetal alloys: The valence-band structure of the metallic glasses $\mathrm{Pd}-\mathrm{Zr}$ and $\mathrm{Cu}-\mathrm{Zr}$. Phys. Rev. Lett. 43, 1134-1137 (1979).

44. He, Q., Cheng, Y.-Q., Ma, E. \& Xu, J. Locating bulk metallic glasses with high fracture toughness: Chemical effects and composition optimization. Acta Mater. 59, 202-215 (2011)

45. Hricovini, K. \& Krempasky, J. UPS and XPS studies of $\mathrm{Fe}_{80-\mathrm{x}} \mathrm{Ni}_{\mathrm{x}} \mathrm{B}_{20}$ metallic glasses. J. Phys. F: Met. Phys. 15, 1321-1329 (1985).

46. Yang, W. M. et al. Magnetic properties of $\left(\mathrm{Fe}_{1-\mathrm{x}} \mathrm{Ni}_{\mathrm{x}}\right)_{72} \mathrm{~B}_{20} \mathrm{Si}_{4} \mathrm{Nb}_{4}(\mathrm{x}=0.0-0.5)$ bulk metallic glasses. J. Magn. Magn. Mater. 335, 172-176 (2013).

47. Huffman, G. P. (eds H. O. Hooper \& A. M. de Graaf) 283-290 (Plenum Press, Newyork-London, 1973)

\section{Acknowledgments}

We appreciate Prof. W. H. Wang and R-W. Li for the insightful discussions. We also thank Dr. C. T. Chang, L. S. Huo and Mr. C. C. Dun, Drew Onken, C. L. Zhao for their assistance in this work. This work was supported by the Natural Science Foundation of Jiangsu Province (No. BK20141124), National Natural Science Foundation of China (No. 51261028, 51271194, 51301188 and 51323004), China Postdoctoral Science Foundation funded project (No. 2013M541804) and Analysis Research for Public Welfare Project of Zhejiang Province (No. 2012C37047).

\section{Author contributions}

W.Y., H.L., B.S., H.L. and Q.L. conceived and designed the research and analysis. K.J. analyzed the photoelectron spectroscopy experimental data. W.Y., H.L., Y.Z., J.H. and A.I. co-wrote the paper. All authors discussed the results and revised the manuscript.

\section{Additional information}

Competing financial interests: The authors declare no competing financial interests.

How to cite this article: Yang, W. et al. Mechanical properties and structural features of novel Fe-based bulk metallic glasses with unprecedented plasticity. Sci. Rep. 4, 6233; DOI:10.1038/srep06233 (2014)

This work is licensed under a Creative Commons Attribution-NonCommercialNoDerivs 4.0 International License. The images or other third party material in this article are included in the article's Creative Commons license, unless indicated otherwise in the credit line; if the material is not included under the Creative Commons license, users will need to obtain permission from the license holder in order to reproduce the material. To view a copy of this license, visit http:// creativecommons.org/licenses/by-nc-nd/4.0/ 